\title{
ОРГАНИЗАЦИЯ ВЗАИМОДЕЙСТВИЯ ГЛАВНЫХ УПРАВЛЕНИЙ МЧС РОССИИ ПО СУБЪЕКТУ РОССИЙСКОЙ ФЕДЕРАЦИИ С ТЕРРИТОРИАЛЬНЫМИ ПОДРАЗДЕЛЕНИЯМИ МВД РОССИИ ПРИ РАБОТЕ ПО ФАКТАМ ПОДЖОГОВ, НЕОСТОРОЖНОГО ОБРАЩЕНИЯ С ОГНЕМ И ИНЫХ ВОЗГОРАНИЙ
}

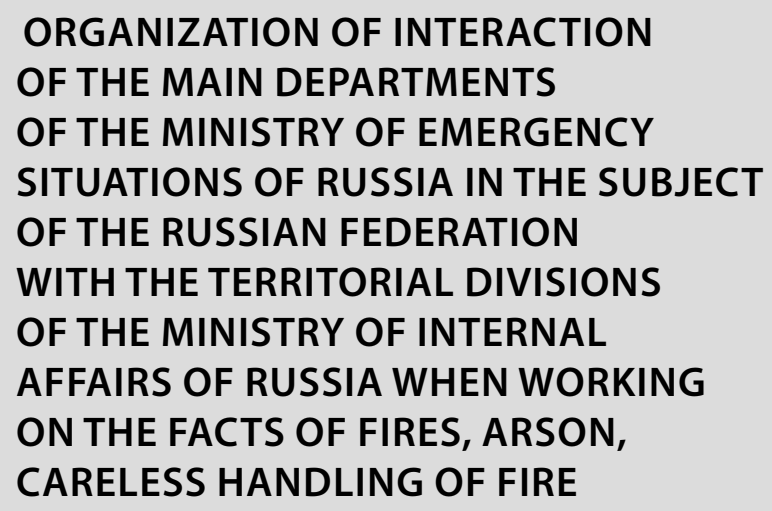

I. Stepanova

Summary. The article reveals the structure of the organization of interaction of the Ministry of Emergency Situations of various levels on the investigation of the facts of ignition, arson and careless handling of fire. The author conducts a study of the specifics of the activities of the departments of the Ministry of Emergency Situations in the subject of the Russian Federation and territorial divisions, structural components of the system and the investigation strategy

Keywords: territorial department of the Ministry of Emergency Situations, investigation strategy, regulatory framework, Interior Ministry units, rapid response, emergency management, emergency.
B качестве основных задач политики государства в сфере национальной безопасности является обеспечение системы национальной безопасности, координация деятельности органов публичной власти и совершенствование находящихся в их распоряжении инструментов[1, 2]. Внутреннюю безопасность можно определить как обеспечение защиты территории и населения нашей страны от чрезвычайных ситуаций как природного, так и техногенного характера. Данные ситуации возникают как вследствие природных явлений, так и негативного воздействия человека на окружающую среду. К таким ситуациям относятся возгорания, поджоги, факты неосторожного обращения с огнем, количество которых сокраща-
Степанова Ирина Александровна Профессор, Академия МЧС России 7503139@gmail.com

Аннотация. В статье раскрывается структура организации взаимодействия органов МЧС России различного уровня по вопросам расследования фактов поджогов, неосторожного обращения с огнем и иных возгораний. Автор проводит исследование специфики деятельности управлений МЧС России по субъекту Российской Федерации и территориальных подразделений, структурных компонентов системы и стратегии расследования.

Ключевые слова: главное управление МЧС России, стратегия расследования, нормативно-правовая база, подразделения МВД РФ, оперативное реагирование, чрезвычайное управление, чрезвычайная ситуация. ется лишь при своевременном расследовании причин таких фактов, а также в результате профилактических мер вторичного плана. Так, в 2019 году в России произошло 471357 пожаров, при которых погибло 8567 чел. и получило травмы 9477 чел.[5]. В 2020 году зарегистрировано 439394 пожара, при которых погибло 8313 чел. и получило травмы 8434 чел. [6]. Это свидетельствует о том, что для проведения профилактических мер необходимо четкое межведомственное взаимодействие - установление и устранение очагов возгорания специалистами МЧС России и расследование причин возникновения ситуации, связанной с пожаром, при передаче материалов в ведомство внутренних дел. 
Актуальность данной статьи обусловлена необходимостью выявления механизмов взаимодействия структурных подразделений МЧС России и органов МВД РФ при выявлении фактов поджогов, неосторожного обращения с огнем, а также возгораний, не относящихся к самовольным.

\section{Шель исслеАования}

Определить различия во взаимодействии субъектов всех уровней при разных видах возгораний для максимальной раскрываемости дел подобного плана и вторичных профилактических мероприятий.

Нормативный, организационный и управленческий аспект данной темы рассматривали многие отечественные авторы, в том числе: В.А. Акимов, Ю.Л. Воробьёв, В.А. Владимиров, А.Ф. Майдыков, А.К. Микеев, Б.Н. Порфирьев. При этом немалое внимание в работах Е.Г. Иванова, А.П. Ипакяна, В.Е. Караганова, В.М. Шишкина уделялось вопросам взаимодействия различных систем, в том числе МЧС России и МВД РФ. Однако, проанализировав данные работы, нами был сделан вывод о том, что проблемы взаимодействия структурных элементов Единой государственной системы предупреждения и ликвидации чрезвычайных ситуаций (РСЧС) проработаны в недостаточной степени.

За основу своей исследовательской деятельности мы брали основные структурные компоненты Министерства Российской Федерации по чрезвычайным ситуациям и ликвидации последствий стихийных бедствий, которые не только осуществляют непосредственно собственные функции[3], но и взаимодействуют с органами МВД. На региональном уровне это взаимодействие долгое время осуществляли региональные центры по делам гражданской обороны, чрезвычайным ситуациям и ликвидации последствий стихийных бедствий[7]; однако после их упразднения и определенных структурных изменений в системе управления, в настоящее время эти функции возложены в основном на органы управления по делам гражданской обороны и чрезвычайным ситуациям в составе или при органах исполнительной власти субъектов Российской Федерации.

Специфика взаимодействия вышеуказанных ведомств заключается в том, что Министерство внутренних дел является тем исполнительным органом, который определяет основные направления государственной политики и нормативного правового регулирования в сфере внутренних дел[4]. Сюда же можно отнести и чрезвычайные ситуации - поджоги, возгорания, которые косвенно или прямо содержат признаки преступлений. Для определения функций тех или иных органов и подразделений МВД РФ и МЧС России в подобных ситуациях, необходимо структурировать их полномочия. Органы МВД включены в ликвидацию последствий чрезвычайных ситуаций через деятельность функциональных групп в направлении оперативного реагирования, чрезвычайного управления и ликвидации последствий поджогов и неосторожного обращения с огнем.

Взаимодействие с органами, ликвидирующими ЧС, начинается уже на первой стадии - оперативного реагирования, когда еще возможно определить максимальное количество факторов, имеющих значение для работы с ситуацией «по горячим следам». Эта деятельность заключается в выявлении лиц, причастных к возникновению данных ситуаций и ликвидации последствий таких ситуаций. При этом главная роль в установлении содержания ситуации и наличия в ней состава преступления отводится органам внутренних дел, которые оценивают масштабность ситуации, причину возникновения, степень мотивированности исполнителей - разную для возгораний, поджогов и неосторожного обращения с огнем. При этом важно определить, какие подразделения министерства внутренних дел занимаются правовым урегулированием деятельности в сфере чрезвычайных ситуаций, какие наделены административными полномочиями, а какие работают непосредственно со случаями и последствиями ЧС.

Чрезвычайное управление должно быть максимально слаженным, т.к. именно от четкости построения стратегии и поведения на пожаре, при ликвидации возгорания зависит не только эффективность действий с минимальными потерями, но и выявление первопричин возникновения такой ситуации, и привлечения к ответственности лиц, виновных в ее возникновении.

Как отмечает Спичкин М.Ю., от МВД России на стадии ликвидации задействованы соединения и воинские части внутренних войск (в настоящее время - Росгвардия), подразделения Государственной автоинспекции МВД России (ГИБДД), отряды мобильные особого назначения, подразделения патрульно-постовой службы, участковые уполномоченные полиции, а также образовательные и научно-исследовательские учреждения МВД России [8] Именно поэтому нами определена важность взаимодействия ведомств МВД РФ и МЧС России на различных этапах работы с возгораниями, поджогами и неосторожным обращением с огнем.

Несомненно, наиболее верным способом закрепления механизма реагирования на чрезвычайные ситуации является нормативное регулирование таких ситуаций на ведомственном уровне, которое при- 
менимо и к ситуациям с поджогами и возгораниями. А в случаях, к которым и относятся поджоги, имеющие намеренный характер, включается еще и человеческий фактор. Это, несомненно необходимо учитывать при организации работы. И именно здесь важно не просто ликвидировать чрезвычайную ситуацию и ее последствия, но и определить исполнителей, предотвратить рецидив, осуществлять вторичную и третичную профилактику. В данном случае к ведомству ЧС подключаются органы МВД с необходимыми для этого имеющимися у них ресурсами.

Кроме того, органы внутренних дел включены в работу еще и косвенно, обеспечивая эффективную работу (оцепления при пожарах, охрана мест поджогов для поисков улик и доказательств, патрулирование и сопровождение лиц, задействованных в расследовании) на стадии ликвидации последствий ЧС. В данном случае, на органы МВД оказывается двойная нагрузка, которая предполагает усиление обеспечения работы с чрезвычайными ситуациями.

\section{Результаты \\ исслеАОвания}

В качестве основных выводов можно определить, что направления взаимодействия структурных подразделений МЧС и органов МВД должны быть направлена на:

- выявление причин возникновения возгораний, пожаров и исполнителей поджогов с точки зрения оценки угроз общественной безопасности и общественному порядку;
- определение общих и видовых признаков возгораний для определения их характера - самопроизвольного либо намеренного;

- обобщение имеющихся научных познаний и практического опыта по предупреждению и ликвидации чрезвычайных ситуаций;

- анализ пожара или возгорания в качестве объекта воздействия со стороны МВД РФ;

- изучение правового регулирования функционирования органов внутренних дел при возгораниях и поджогах;

- определение факторов, влияющих на эффективность работы органов МВД РФ при поджогах и возгораниях;

- определение и обоснование принципов применения сил и средств органов внутренних дел при ликвидации последствий чрезвычайных ситуаций;

- исследование взаимодействия территориальных органов внутренних дел с аварийно - спасательными службами главных управлений МЧС России по субъектам Российской Федерации.

Взаимодействие главных управлений МЧС России по субъекту Российской Федерации с территориальными подразделениями МВД России должно осуществляться на всех этапах работы с поджогами, возгораниями и неосторожным обращением с огнем не только с учетом масштабности ситуации, степени пожара и возможных негативных последствий, но и факторов возникновения - случайно, непреднамеренно, намеренно - в целях максимального использования ресурсов обоих ведомств.

\section{ЛИТЕРАТУРА}

1. Указ Президента РФ от 02.07.2021 N400 «0 Стратегии национальной безопасности Российской Федерации» // Собрание законодательства РФ.2021. — № 27 (ч. 2).— Ст. 5351.

2. Указ Президента РФ от 10.01.2000 года N2 «0 Концепции национальной безопасности Российской Федерации»

3. Указ Президента РФ от 11.07.2004 N868 (ред. от 01.10.2021) «Вопросы Министерства Российской Федерации по делам гражданской обороны, чрезвычайным ситуациям и ликвидации последствий стихийных бедствий»

4. Указ Президента РФ от 01.03.2011 N248 (ред. 0т 25.08.2021) «Вопросы Министерства внутренних дел Российской Федерации»

5. Государственный доклад «0 состоянии защиты населения и территорий Российской Федерации от чрезвычайных ситуаций природного и техногенного характера в 2019году». М.: МЧС России; ФГБУ ВНИИ ГОЧС (ФЦ), 2020. — 259 с. [Электронный ресурс] // Официальный сайт Министерства Российской Федерации по делам гражданской обороны, чрезвычайным ситуациям и ликвидации последствий стихийных бедствий.—Режим доступа: https:// www.mchs.gov.ru (дата обращения: 08.10.2021).

6. Государственный доклад «0 состоянии защиты населения и территорий Российской Федерации от чрезвычайных ситуаций природного и техногенного характера в 2020году». М.: МЧС России; ФГБУ ВНИИ ГОЧС (ФЦ), 2021.— 264 с. [Электронный ресурс] // Официальный сайт Министерства Российской Федерации по делам гражданской обороны, чрезвычайным ситуациям и ликвидации последствий стихийных бедствий.— Режим доступа: https:// www.mchs.gov.ru (дата обращения: 08.10.2021).

7. Игнатьев В.Б. Правовое регулирование межведомственного взаимодействия МВД России и МЧС России в чрезвычайных ситуациях: дис., канд. юр. наук — СПб., 2006-195 c.— URL: http://www.dissercat.com/content/pravovoe-regulirovanie-mezhvedomstvennogovzaimodeistviya-mvd-rossii-i-mchsrossii-v-chrezvy. (дата обращения: 08.10.2021). 
8. Спичкин М.Ю., Томилина Е.П. Некоторые аспекты взаимодействия МЧС России и МВД России по предупреждению и ликвидации последствий ЧС // Проблемы обеспечения безопасности при ликвидации последствий чрезвычайных ситуаций. 2014. № 1. URL: https://cyberleninka.ru/article/n/ nekotorye-aspekty-vzaimodeystviya-mchs-rossii-i-mvd-rossii-po-preduprezhdeniyu-i-likvidatsii-posledstviy-chs (дата 0бращения: 08.10.2021).

9. Арзамасцев Н.И. Административно-правовое обеспечение органами внутренних дел общественной безопасности при чрезвычайных ситуациях техногенного характера: автореф. дис. канд. юрид. наук. М., 2002.— 20 c. URL: http://www.dissercat.com/content/pravovoe-regulirovanie-mezhvedomstve nnogovzaimodeistviya-mvd-rossii-i-mchs-rossii-v-chrezvy. (дата обращения: 08.10.2021).

10. Василишин И.И. Взаимодействие подразделений МВД России и МЧС России в чрезвычайных ситуациях: Правовые и организационные вопросы: автореф. дис. канд. юрид. наук. М., 2004. - 24 с.

() Степанова Ирина Александровна ( 7503139@gmail.com ).

Журнал «Современная наука: актуальные проблемы теории и практики»

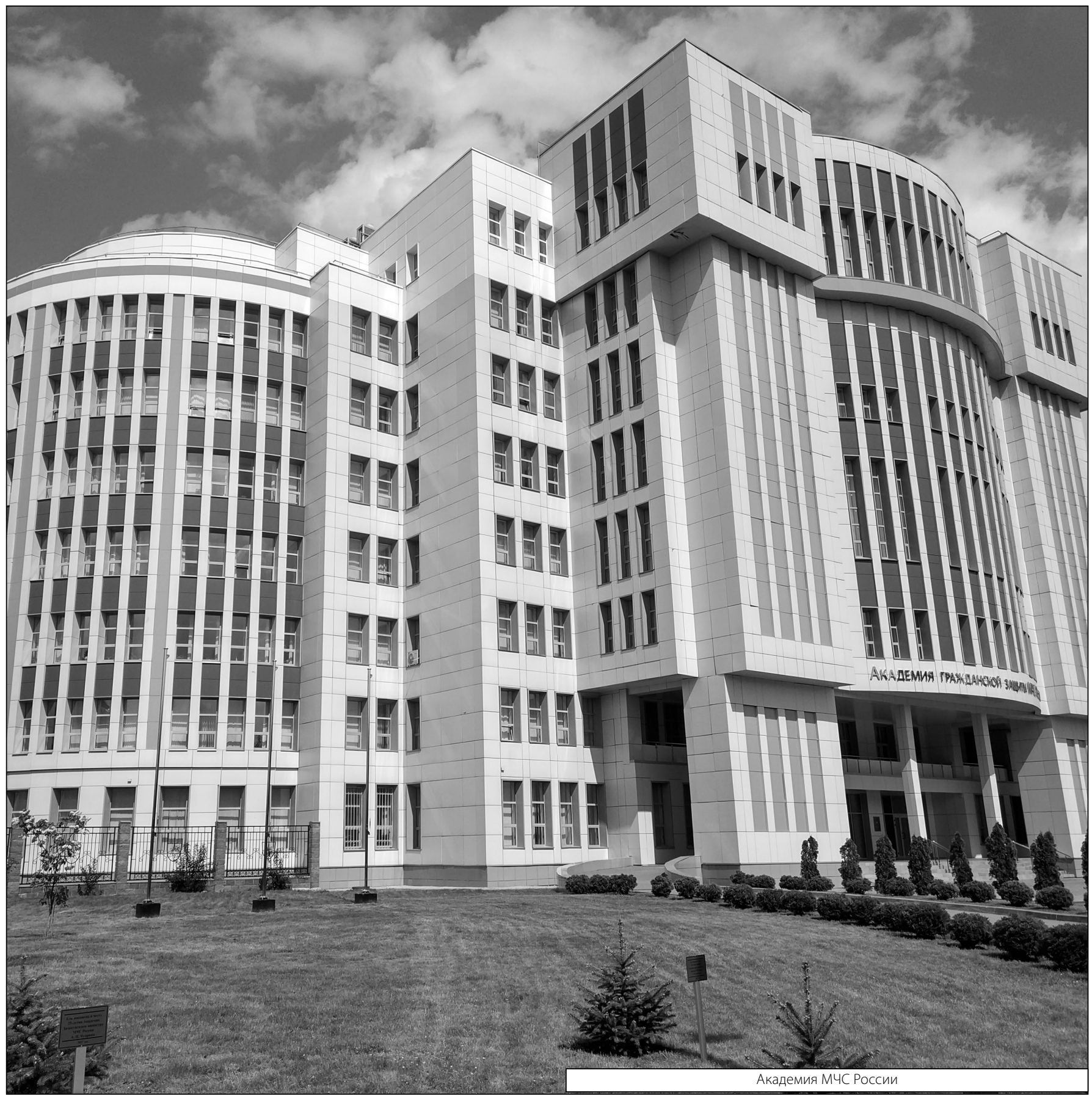

